\title{
HEALTH IN BRAZIL - OPTIMISTIC OUTLOOK?
}

\author{
A saúde no Brasil - perspectivas otimistas? \\ Florentino CARDOSO \\ President of the Brazilian Medical Association
}

T he Brazilian health system is mixed: public and private. There is a public system - SUS and the system of supplementary health (health insurance companies). The SUS was very well designed and implemented for about 25 years (1988). ANS - National Agency of Supplemental Health is even younger, created in January 2000. ANS is the regulatory agency under the Ministry of Health. The two systems coexist, but do not interact properly.

A hundred and fifty million people depend exclusively on SUS and health operators have about 52 million users. Several of these users also use SUS on health demands and, in different ways, all Brazilians use SUS (health surveillance, for example).

Public health funding has not been sufficient to meet the demands of the people. The share of spending occurs in three levels, but there is a progressive exemption from federal portion, sacrificing increasingly the federative states and especially the municipal budget. About 12 years the share of federal spending on health was around $60 \%$ of the whole. Today only $42 \%$, as around $58 \%$ come from states and municipalities. Municipalities must apply at least $12 \%$ and states at least $15 \%$ of its budget on public health. The supplementary system, which serves about $25 \%$ of the population, has more resources than the public system.

While we recognize improvements in the public health system, its management is not qualified, because there is predominant political and electoral bias in the choice of the managers; instead of this, we should expect to have strong technical influence. Also, is not used adequately the largest and most qualified efficiency of the supplemental health care sector. Besides not having enough resources, they are badly applied and associated to the rampant corruption that persists in our country, that has good, orderly and worker people.

We believe that public-private partnerships and effective prioritization of the health sector could bring more gains to the system, directly benefiting the population, especially the poor and needy, already suffering a lot due to poverty, delays in education, infrastructure and safety.

Not only suffers the health care, but also teaching and research. The assistance should prioritize access to quality, ensuring the two main entry points to the system: primary or basic and emergency care. An integrated network should exist, with permanent control and evaluation, with referral and counter-referral of patients using SUS.

The teaching in the sector has been less than optimal. Several medical schools were opened, in the majority as private schools and without conditions for functioning: good physical structure for practical activities, as well as current curriculum for Brazilian medical needs and qualified teachers. The federal government claims that our medical schools train few students each year, and insists to authorize new vacancies, 40-50 every year. We need to better educate our doctors and other healthcare professionals. The same happens in post-graduate level where it is also prioritized the quantity, over quality. Let us form the required amount with proper qualifications; it is possible and is the best way.

The residency, which has been the gold standard for care, has suffered from misplaced interventions with high dictatorial meddling. There is no planning for the number of health professionals (doctors, nurses, dentists, physiotherapists etc.) for today or for the next 10, 20 or 30 years. We continue improvising, wanting to import models from other countries, making use of them with patterns that are not adequate to our reality. Why the government managers say they want in Brazil 2.7 physicians per 1,000 population? To be equal to the UK? Well, today we have several cities that outperform this index: Brasilia, Rio de Janeiro, São Paulo and others; even there, the public system keep on being chaotic - analyzed by the offered quality. The waiting list of patients for consultations, complementary exams and surgical procedures is enormous. Several of these patients rely upon themselves in emergencies, overloading them and many die from preventable causes.

Clinical research in Brazil, the world's seventh largest economy, also shames us when compared to many countries. There stubborn bureaucracy and overlapping of powers, among many inefficiencies, greatly delays the analysis of several studies. We are behind in clinical research from the point we are able to be. All of us lose: patients, researchers and our country Brazil. Some patients fail to participate in studies that can mean gains in quality of life and even cure. Our researchers lose several opportunities, especially studies in phase I and II. At the end, Brazil loses because the gain is undeniable; research leads to the development, create wealth and currencies.

However, if much can and must be done, and if we realize that the people in charge cannot do, we should use our democratic power to change this sad scenario. Brazil is much more than any of us, any political party. The health is our greatest duty and the Brazilian population deserves respect! 